\title{
PARALELO ENTRE A TEORIA DA JUSTIÇA COMO EQUIDADE DE JOHN RAWLS E A IGUALDADE DE CAPACIDADES DE AMARTYA SEN
}

\author{
Irenice Tressoldi \\ Autora correspondente. Universidade do Oeste de Santa Catarina - Unoesc. Av. Nereu Ramos, 3777-D - Bairro Seminário. \\ Chapecó /SC, Brasil. CEP 89813-000. http://lattes.cnpq.br/8082895150627968. https://orcid.org/0000-0002-0826-3994. \\ ire.tressoldi@hotmail.com \\ Robison Tramontina \\ Universidade do Oeste de Santa Catarina - Unoesc. Chapecó /SC, Brasil. http://lattes.cnpq.br/5066201986998249. \\ https://orcid.org/0000-0002-1852-4983.robison.tramontina@unoesc.br.
}

RESUMO

A teoria da justiça como equidade cunhada por John Rawls representa um marco no debate filosófico e político acerca da distribuição da justiça. Em uma abordagem que se cinge com a teoria da justiça como equidade, Amartya Sen observa que as liberdades individuais e coletivas devem ser priorizadas em relação ao desenvolvimento econômico. Pretende-se com esta pesquisa abordar o paralelo existente entre a teoria da justiça de John Rawls e Amartya Sen, a partir das críticas feitas por Sen à teoria formulada por Rawls. O problema imanente à pesquisa concentra-se, assim, nos seguintes termos: Quais as semelhanças e contraposições entre a teoria da justiça como equidade de John Rawls e a justiça focada nas realizações de Amartya Sen? Para desenvolver a pesquisa qualitativa utiliza-se o método dedutivo, com a análise de conceitos e premissas da literatura científica acerca dos temas pesquisados, mediante pesquisa teórica orientada pela leitura de livros e de artigos publicados em revistas científicas. A hipótese associada ao questionamento formulado indica que, para Sen, enquanto uma teoria da justiça de cunho transcendental, como é a de Rawls, pretende entender o que seriam as instituições perfeitamente justas, a sua abordagem de comparação focada em realizações quer encontrar respostas para a questão de como a justiça pode ser promovida.

Palavras-chave: Desenvolvimento humano; distribuição de justiça; justiça social; justiça como equidade.

PARALLEL BETWEEN JOHN RAWLS' JUSTICE AS FAIRNESS AND AMARTYA SEN'S CAPACITY EQUALITY ABSTRACT

John Rawls' theory of justice as fairness represents a mark in the philosophical and political debate about the distribution of justice. In an approach that connects with the theory of justice as fairness, Amartya Sen argues that individual and collective freedoms must be prioritized over economic development. This research aims to approach the parallel existing between the theory of justice by John Rawls and Amartya Sen, based on the criticisms made by Sen about the theory formulated by Rawls. The problem inherent in this research is thus concentrated in the following terms: what are the similarities and contrasts between John Rawls' theory of justice as fairness and Amartya Sen's justice focused on achievements? To develop the qualitative research, the deductive method is used, with an analysis of concepts and premises of the scientific literature on researched themes, through theoretical research guided by the reading of books and articles published in scientific journals. The hypothesis associated with the formulated questioning indicates that, for Sen, while a theory of justice with a transcendental approach, such as Rawls', intends to understand what it would be like perfectly just institutions, his comparison approach focused on achievements aims to find answers to the question of how justice can be promoted.

Keywords: Human development; distributive justice; social justice; justice as fairness.

Recebido em: 30/3/2021

Aceito em: 19/5/2021 


\section{INTRODUÇÃO}

Na década de 70 John Rawls lançou a obra "Uma teoria da justiça", na qual formulou a teoria da justiça como equidade. A ótica filosófica rawlsiana reacendeu os debates acerca da distribuição da justiça, conferindo novo vigor à tradicional teoria do contrato social. Desde então, a abordagem da justiça como equidade é uma referência a teóricos políticos e filósofos contemporâneos, que comentam suas ideias de justiça social e teoria política a partir da perspectiva de John Rawls.

A teoria da justiça como equidade trata-se de uma opção ao utilitarismo, na qual se busca uma alternativa para distribuição de bens e riquezas na sociedade, a partir da escolha de princípios aplicáveis à estrutura básica da sociedade em uma posição original, que é uma espécie de contrato social hipotético e a-histórico.

Ocorre que a solução das desigualdades sociais pode provir de concepções diversas de justiça distributiva, razão pela qual o tema da distribuição de direitos e liberdades em uma sociedade é uma questão filosófica complexa e de difícil resposta.

Amartya Sen destaca-se, nesse contexto, ao identificar a necessidade de o desenvolvimento voltar-se às capacidades dos cidadãos, priorizando-se a ampliação das liberdades individuais e coletivas em relação ao desenvolvimento econômico. A garantia contínua das liberdades é, assim, um modo de ampliar a capacidade dos indivíduos de levarem uma vida que têm razão para buscar, bem como de participarem das atividades da sociedade.

A exemplo de outros autores contemporâneos que debatem a distribuição de bens e liberdades na sociedade, Sen formula sua abordagem em diálogo com a teoria da justiça como equidade de John Rawls. Embora Sen parta da formulação de críticas à teoria rawlsiana, há muitas questões comuns em suas teorias: ambas tratam de concepções de justiça de cunho igualitarista, buscam solucionar desigualdades e pobrezas em sociedades democráticas contemporâneas e rejeitam proposições utilitaristas.

Com esta pesquisa pretende-se abordar o paralelo existente entre as teorias da justiça de John Rawls e Amartya Sen, a partir das críticas feitas por este à teoria formulada pelo primeiro. O problema imanente à pesquisa concentra-se, assim, nos seguintes termos: Quais as semelhanças e contraposições entre a teoria da justiça como equidade de John Rawls e a justiça focada nas realizações de Amartya Sen?

Para o desenvolvimento da pesquisa qualitativa utiliza-se o método dedutivo, com a análise de conceitos e premissas da literatura científica acerca dos temas investigados, mediante pesquisa teórica orientada pela leitura de livros e de artigos publicados em revistas científicas.

Inicialmente será apresentada a concepção de justiça como equidade de John Rawls. Em seguida, será feita uma abordagem da concepção de Amartya Sen de justiça social, focada em realizações. Por fim, serão destacadas as críticas de Sen à teoria rawlsiana, com uma sucinta comparação entre as abordagens.

A hipótese associada ao questionamento formulado indica que, para Sen, enquanto uma teoria da justiça de abordagem transcendental, como é a de Rawls, pretende entender o que seriam as instituições perfeitamente justas, a sua abordagem de comparação focada em realizações quer encontrar respostas para a questão de como a justiça pode ser promovida. 


\section{JUSTIÇA COMO EQUIDADE DE JOHN RAWLS}

A teoria da justiça como equidade cunhada por John Rawls é a teoria moderna da justiça que mais repercute debates filosóficos, jurídicos e sociológicos. Nos anos 70, John Rawls firmou a sua teoria a partir da formulação de uma posição original hipotética e a-histórica, na qual os cidadãos representativos, em situação de igualdade, por trás de um véu da ignorância, escolhem dois princípios de justiça aplicáveis à estrutura básica da sociedade. Os dois princípios escolhidos destinam-se a apresentar a melhor opção em assuntos como a distribuição de direitos e deveres e a divisão das vantagens da cooperação social justa, bem como servem de base para todas as demais decisões políticas e construções sociais (RAWLS, 2008).

A teoria rawlsiana é deontológica, pois o justo prevalece sobre o bem. Rawls retoma os preceitos de Kant, que considera o homem um fim em si mesmo e não como um meio para o bem da maioria. Vai além, contudo, abordando um debate institucional da justiça, a partir de uma referência à estrutura básica da sociedade, em que a noção de justiça é um atributo essencial para a cooperação social.

Freeman (2007) destaca que a natureza hipotética do acordo de Rawls na posição original assemelha-se à ideia do contrato original de Kant, que também é um contrato social hipotético e não real. Na leitura de Rawls, a tradição do contrato social, desde Hobbes, Locke e Rousseau até Kant, considera o contrato social como um pensamento hipotético, destinado a demonstrar quais são os termos mais razoáveis de cooperação entre pessoas racionais e iguais.

A teoria da justiça como equidade caracteriza-se, assim, como uma teoria contratualista, em razão da previsão da posição original, a qual se relaciona ao ponto de partida do contrato social de Rawls. A posição original é uma construção hipotética representativa e a-histórica, destinada a apresentar a melhor opção em assuntos como distribuição de direitos e deveres e a divisão das vantagens da cooperação social.

Na concepção rawlsiana, a justiça de uma sociedade funda-se na igualdade entre os seres humanos como valor intrínseco. As instituições devem, por isso, fornecer o suporte necessário, em termos de direitos, oportunidades, liberdades e recursos sociais, para que cada um possa se desenvolver de acordo com as suas próprias convicções morais.

Há duas ideias que são inerentes à teoria rawlsiana: a sociedade como um sistema de cooperação e a estrutura básica da sociedade. A cooperação social é, para Rawls, um elemento indispensável a uma sociedade bem ordenada. Ligada à ideia de pessoas livres, razoáveis e racionais, a cooperação social pretende a formação de um ambiente social melhor para todos, no qual estariam dispostos a seguir as regras que ordenam a sociedade (RAWLS, 2008).

A sociedade é, assim, uma espécie de parceria que objetiva o benefício mútuo daqueles que resolvem participar dela. A questão central da justiça social relaciona-se às condições dessa parceria e ao modo como os seus benefícios serão distribuídos entre os participantes (JOHNSTON, 2018).

Nessa perspectiva, a unidade da sociedade é baseada na aceitação de uma concepção política de justiça por parte dos cidadãos, ligada à ideia de bem, o que garante a aplicação dos princípios da justiça e assegura a estabilidade social. 
No que respeita à estrutura básica da sociedade, Rawls (2008) destaca que a justiça de um arranjo social depende de como deveres e direitos fundamentais são atribuídos, bem como da medida das oportunidades econômicas e das condições sociais de diversos setores da sociedade. Por isso, a teoria da justiça como equidade parte da formulação de princípios, que servem de baliza para a estrutura básica da sociedade.

É importante frisar que os arranjos sociais são justos para Rawls (2008) a partir do conceito de justiça procedimental pura, segundo o qual o método justo prevalece sobre o resultado, pois é aceito por todos. Proporciona, assim, uma confiança no seu próprio valor e de que seus planos terão chances exitosas, uma vez que as pessoas agirão de maneira justa desde que seus atos estejam em conformidade com as exigências das instituições.

Esse arranjo, na perspectiva do liberalismo político, resultaria em uma sociedade bem ordenada, a qual, segundo Rawls (2011), significa três coisas: 1) é uma sociedade na qual cada um aceita e sabe que todos os demais cidadãos aceitam os mesmos princípios de justiça; 2) reconhece-se publicamente que a estrutura básica da sociedade institui os princípios de justiça que todos aceitam e 3) é aquela na qual os cidadãos têm um senso de justiça efetivo, razão pela qual agem em conformidade com as instituições que consideram justas.

Embora reforce sua teoria deontológica de justiça, Rawls insere o bem em seu projeto com uma preocupação voltada a uma concepção geral de bem, no sentido de proporcionar o básico a todos e permitir a liberdade para cada cidadão perseguir seu próprio plano de vida.

Nesse passo, a escolha de bens primários, tratados como bens que todos escolheriam, antecede a escolha dos princípios de justiça, pois são bens necessários para tal fim. Consoante Rawls (2008), bens primários são coisas que os cidadãos, como seres racionais, sempre optariam por ter mais do que menos. São eles: autoestima ou autorrespeito, direitos, liberdades e oportunidades, renda e riqueza.

Com uma quantidade maior de bens e riquezas, conclui Rawls (2008), haverá um maior êxito na realização das intenções e na promoção dos objetivos pessoais, sejam eles quais forem. Assim, por mais que as pessoas possam desejar outros bens que não sejam os primários, estes serão sempre essenciais, razão pela qual são escolhidos antes mesmo dos princípios da justiça.

Rawls (2011) argumenta que a justiça como equidade e sua posição original revelam uma concepção de justiça firmada com base em um acordo político racional, bem-informado, voluntário e público, compartilhado pelos cidadãos. Alerta o autor, contudo, que a concepção de justiça deve ser independente das doutrinas filosóficas e religiosas incomensuráveis e conflitantes que os cidadãos professam, a fim de alcançar uma razão compartilhada de justiça. Por essa razão, o liberalismo político busca uma concepção de justiça que possa conquistar o apoio de um consenso sobreposto de doutrinas religiosas, filosóficas e morais razoáveis em uma sociedade que seja regulada por tal concepção.

Conforme já destacado, na teoria da justiça como equidade o aspecto de sua distribuição funda-se na previsão dos dois princípios de justiça, que constituem o objeto do acordo original. Os dois princípios de justiça são escolhidos apoiados nas doutrinas razoáveis abrangentes, que formam um consenso sobreposto, e aplicam-se à estrutura básica da sociedade, a qual compreende suas principais instituições sociais, tais como a constituição política, as estruturas econômicas fundamentais e as principais organizações sociais, no intuito de formar uma sociedade bem ordenada. 
Referidos princípios são aqueles que "[...] pessoas livres e racionais, interessadas em promover seus próprios interesses, aceitariam em uma situação inicial de igualdade como definidores das condições fundamentais de uma associação" (RAWLS, 2008, p. 14-15). Os princípios devem ser escolhidos por trás de um véu de ignorância, o que significa que as pessoas na posição original desconhecem sua situação na sociedade, classe, status social ou sorte na distribuição dos recursos e das habilidades naturais, inteligência, força, etc., a fim de evitar que alguém seja favorecido ou desfavorecido pelas circunstâncias pessoais. Nisso se apoia denominação de justiça como equidade, tendo em vista que "[...] os princípios da justiça são definidos por acordo em uma situação inicial que é equitativa" (RAWLS, 2008, p. 14-15).

Assim, na posição original, em situação de igualdade e equidade, sob o véu da ignorância, Rawls (2008) acredita que as pessoas livres e iguais escolheriam dois princípios de justiça: o primeiro trata de liberdades básicas iguais para todos os cidadãos e o segundo relaciona-se à equidade social e econômica, transmitida por meio da igualdade equitativa de oportunidades e do princípio da diferença.

Por meio do primeiro princípio conferem-se iguais liberdades para os cidadãos. De acordo com a justiça como equidade, deve-se estabelecer um sistema de iguais liberdades para todos, compatível com os direitos e as liberdades dos outros indivíduos. Nesse arranjo, não devem ser privilegiadas circunstâncias naturais (habilidades naturais) ou fatores que independem dos agentes, como condições sociais e familiares privilegiadas. As diferenças produzidas por esses fatores devem ser equilibradas com a aplicação do primeiro princípio nas instituições básicas da sociedade (RAWLS, 2008).

Nesse passo, Rawls (2008) lista como liberdades básicas integrantes do primeiro princípio, que devem ser iguais: liberdade política (o direito ao voto e a exercer cargo público) e a liberdade de expressão e reunião; liberdade de consciência e de pensamento; a liberdade individual, que compreende a proteção contra a opressão psicológica, a agressão e a mutilação (integridade da pessoa); direito à propriedade pessoal e a proteção contra prisão e detenção arbitrárias, segundo o conceito de Estado de Direito.

Dizer que essas liberdades são básicas significa não apenas afirmar que são essenciais ou importantes, mas também que são inalienáveis, mesmo que por ato voluntário do próprio agente que as possui, uma vez que as liberdades básicas fundam-se em um ideal moral de pessoas como agentes autônomos, livres e equânimes, que têm um especial interesse em manter sua liberdade, sua igualdade e sua independência.

Tal dimensão das liberdades básicas na estrutura fundante das instituições, confere condições para fortalecer liberdades jurídicas efetivas nas bases sociais. Uma vez garantidas, as liberdades básicas fornecem uma estrutura sólida para desenvolvimento dos poderes morais e da dignidade dos cidadãos, o que os torna efetivamente livres.

Embora inalienáveis, nenhuma das liberdades básicas é absoluta, ou seja, nenhuma delas é individualmente mais importante do que outras. Desse modo, conflitos entre liberdades básicas devem ser resolvidos de modo a manter um esquema totalmente adequado de liberdades básicas, o que significa que elas somente podem ser restringidas para proteger e manter as próprias liberdades básicas necessárias para efetivo desenvolvimento dos poderes morais dos cidadãos. 
As liberdades básicas são, portanto, estabelecidas como aquelas liberdades necessárias para equilibrar o desenvolvimento das habilidades naturais e para desenvolver adequadamente e exercer completamente as capacidades morais dos cidadãos.

No que diz respeito ao segundo princípio, Rawls (2008) aplica-o à distribuição da renda e riqueza, a qual não precisa ser igual, mas tão somente vantajosa para todos, e à estruturação de organizações que fazem uso de diferenças de autoridade e responsabilidade. Embora Rawls admita desigualdades econômicas e sociais, limita-as ao máximo benefício possível dos menos favorecidos, de modo compatível com a poupança justa, bem como que estejam vinculadas a cargos e posições abertos a todos em condições de igualdade equitativa de oportunidades.

Rawls (2008) divide o segundo princípio da justiça como equidade em duas partes: a igualdade equitativa de oportunidades e o princípio da diferença.

A igualdade equitativa de oportunidades que Rawls propõe vai além da igualdade formal de oportunidades do liberalismo clássico de posições sociais abertas para fixar uma igualdade mais substantiva, corrigindo desvantagens sociais decorrentes das diferenças de classes. Em "Uma teoria da justiça" Rawls menciona dois requisitos impostos pela igualdade equitativa de oportunidades (embora ele observe que há mais), consistentes em evitar acumulações excessivas de propriedade e riqueza e manter iguais oportunidades de educação a todos (FREEMAN, 2007).

A aplicação desse princípio relaciona-se com a justiça procedimental pura, na qual uma justa distribuição de renda, riquezas, poderes e posições de autoridade (índice de bens primários) será resultante da conformidade com as instituições de base.

Em complemento à igualdade equitativa de oportunidades, o princípio da diferença, segunda parte do segundo princípio, pressupõe que as desigualdades econômicas e sociais devem ser empregadas de modo que sejam vantajosas para todos, especialmente para os grupos que estão em pior situação (RAWLS, 2008).

Nesse viés, convém destacar que o princípio da diferença não estabelece o sistema econômico de modo a permitir que os benefícios cheguem aos desfavorecidos como um reflexo tardio da distribuição. Pelo contrário, o princípio da diferença concentra-se primeiro nas expectativas dos menos favorecidos em determinar o sistema de propriedade pessoal e controle, produção e troca. Logo, um sistema econômico justo sob o princípio da diferença faz os menos favorecidos da sociedade melhores do que os menos favorecidos em qualquer outro sistema econômico, desde que seja compatível com as liberdades básicas e a igualdade equitativa de oportunidades (FREEMAN, 2007).

Assim sendo, na teoria da justiça como equidade de Rawls a maximização dos benefícios dos menos favorecidos da sociedade pelo princípio da diferença, conforme mencionado anteriormente, não pode violar liberdades básicas, nem a igualdade equitativa de oportunidades. Assim, desigualdades em renda e riqueza são permitidas desde que resultem em benefício de todos, especialmente da parcela menos favorecidos da sociedade, mas também com a condição de que essas desigualdades não ofendam a igualdade equitativa de oportunidades, ou o igual valor das liberdades básicas dos demais membros da sociedade ou mesmo daqueles menos favorecidos. 
O primeiro princípio da justiça rawlsiana tem prioridade lexical sobre o segundo , o que significa que as liberdades básicas devem ser garantidas antes da distribuição do produto social. Tal qual o princípio da igualdade de liberdades básicas tem prioridade lexical sobre o segundo princípio, o princípio da igualdade equitativa de oportunidades tem prioridade lexical sobre o princípio da diferença, a fim de possibilitar aos cidadãos meios efetivos para desenvolver e treinar suas habilidades naturais, para que possam tirar proveito máximo das oportunidades abertas e alcançar o respeito próprio e seu status de cidadãos iguais, limitando, desse modo, as desigualdades sociais.

Dessa reflexão é possível ponderar que uma sociedade que distribui de forma equânime a justiça - pressupondo-se ser esta aquela na qual os indivíduos têm possibilidade de exercer suas liberdades fundamentais, poderes e cidadania (esta entendia no sentido de participar das escolhas e decisões políticas e sociais) de maneira completa e plena - é aquela na qual há uma justa e concreta (não necessariamente igual) divisão de renda e riquezas. Isso porque a garantia de direitos, liberdades e poderes afastada de um ambiente social e econômico favoráveis ao seu desenvolvimento compromete a eficácia do exercício desses direitos e liberdades.

As preocupações de Rawls com a igualdade formal no que diz respeito às liberdades fundamentais e com a igualdade material na distribuição de renda e riqueza e no acesso aos cargos e posições na sociedade são evidentes na formulação da teoria da justiça como equidade, pois não basta a liberdade formal se não forem acompanhadas de liberdade material.

Além disso, ao defender a estrutura básica da sociedade como o principal objeto da sua teoria, Rawls concentra-se nas oportunidades, não nos resultados finais (JOHNSTON, 2018). Isso significa dizer que Rawls preocupa-se mais com um ponto de partida igual para todos do que um resultado igual. Por isso, por mais que o princípio da diferença pareça preocupar-se com os resultados da distribuição, a sua base concentra-se ainda na estrutura básica da sociedade.

Ao priorizar a distribuição da renda, riquezas e poderes aos membros menos favorecidos da sociedade, a teoria de Rawls possibilita um desenvolvimento mais pleno das instituições sociais e dos próprios indivíduos, uma vez que o desfrute dos poderes sociais, políticos e morais só é passível de efetivação com a distribuição de renda e riquezas, que se reverte na concretização das liberdades dos cidadãos.

No ideal de sociedade rawlsiano, o bem e o justo são compatíveis e isso torna o conjunto da sua teoria congruente. A ideia de sociedade justa na formulação de Rawls transcende os interesses individuais. Em sua perspectiva de sociedade bem ordenada e justa, os indivíduos são vistos como cidadãos iguais, com valor intrínseco, razão pela qual possuem importância para a sociedade e para o Estado, o qual não pode Ihes impor uma ideia única ou limitada de bem. Disso se extrai que cada um tem liberdade para perseguir seu plano de vida conforme suas próprias convicções de bem e de vida boa, restando ao Estado garantir o mínimo necessário, ou seja, os bens básicos, para que os indivíduos possam ir em busca de qualquer projeto de vida. Na posse dos bens necessários, o indivíduo poderá usar da sua racionalidade para escolher qual caminho trilhar diante dos tantos disponíveis e considerando a variedade de talentos e inteligência dos seres humanos. O Estado limita sua atuação à distribuição de bens fundamentais. 
Apresentadas as linhas gerais da teoria rawlsiana que influem na pesquisa, passa-se, a seguir, à análise da abordagem da igualdade de capacidades de Amartya Sen.

\section{A IGUALDADE DE CAPACIDADES DE AMARTYA SEN}

Amartya Sen é um economista indiano, cocriador do IDH, que desenvolveu sua obra " $A$ ideia de justiça" a partir de uma interlocução com a teoria da justiça como equidade de John Rawls, a quem a obra é, inclusive, dedicada. A crítica à teoria neocontratualista rawlsiana é formulada com suporte em um enfoque comparativo. Enquanto Rawls defende uma justiça transcendental, a partir de um arranjo institucional, Sen parte de uma justiça comparativa, refletindo sobre problemas não alcançados pelas teorias transcendentais.

Sen (2011) inicia o texto de "Uma ideia de justiça" abordando que a racionalidade do iluminismo europeu se dividiu em duas vertentes. Uma que se concentrou na identificação de arranjos sociais perfeitamente justos, na qual a caracterização das instituições justas é a tarefa mais importante e a única identificadora da teoria da justiça. Estruturadas em torno de um contrato social hipotético, as abordagens contratualistas, como de Locke, Rousseau, Kant e Rawls, são presenças influentes na filosofia política contemporânea.

Uma outra faceta do iluminismo adotou uma variedade de abordagens que comparam diferentes vidas que as pessoas podem levar, influenciadas pelas instituições, mas também pelo comportamento real das pessoas, pelas interações sociais e outros determinantes significativos. Incluem-se nessa abordagem, à qual Sen também se filia, conhecidos filósofos como Smith, Condorcet, Bentham, Marx, Mill (SEN, 2011).

Sen parte do pressuposto de que a busca da razão é determinante básico do comportamento bom e justo. Ela é indispensável e mesmo as emoções têm um lugar significativo dentro da razão. Para este autor (2011), ambas desempenham um papel importante na racionalidade.

A partir desse enfoque comparativo do iluminismo, Amartya Sen traz em suas obras uma abordagem para o desenvolvimento humano a partir da perspectiva da promoção de capacidades como uma forma de liberdade. A ideia central abordada pelo autor aponta que o enfoque do desenvolvimento a partir da quantidade de renda é insuficiente para aferir o quanto essa renda representa para o desenvolvimento humano, no sentido de convertê-la em qualidade de vida.

Assim, na concepção de Sen $(2010,2011)$, o desenvolvimento não deve se atrelar unicamente a fatores como o Produto Interno Bruto, rendas, industrialização, avanço tecnológico ou modernização social. Embora o autor reconheça que esses fatores contribuam para a expansão das liberdades, especialmente no que diz respeito ao acesso a bens, produtos e serviços que melhoram a qualidade de vida, eles não podem ser os únicos considerados quando se trata de desenvolvimento humano. Desse modo, o crescimento econômico deve estar relacionado à melhoria de vida dos indivíduos e ao fortalecimento das liberdades. Por isso, o efetivo e amplo acesso a serviços como educação e saúde, bem como a garantia de direitos civis e de cidadania livres, são considerados fundamentais para a promoção e expansão de liberdades.

Amartya Sen defende a priorização das liberdades para garantir o desenvolvimento de uma comunidade por duas razões principais: uma razão avaliatória, segundo a qual a "[...] 
avaliação do progresso tem de ser feita verificando-se primordialmente se houve o aumento da liberdade das pessoas" (SEN, 2010, p. 17), e uma razão da eficácia, uma vez que "a razão do desenvolvimento depende inteiramente da livre condição de agente das pessoas" (SEN, 2010, p. 17). Nessa perspectiva, as liberdades são tanto o meio quanto o fim do desenvolvimento e destacam os valores e possibilidades das pessoas de viverem uma vida que têm razão para valorizar.

A liberdade para Amartya Sen tem, também, um sentido amplo, que abrange tanto a ausência de obstáculos que impeçam o exercício de direitos quanto a existência de meios ou instrumentos para que as pessoas exerçam suas capacidades. Por isso, a liberdade no sentido de haver oportunidades abertas para as pessoas buscarem seus objetivos é, para Sen, tão importante quanto a existência de liberdade no processo de escolha individual. Dito de outra forma, a certeza de que não há uma coação para tomar uma ou outra decisão motivada por circunstâncias ou limitações que estão fora do controle do agente tem o mesmo valor de importância do que a existência de oportunidades abertas.

Sen (2010) destaca com isso que o núcleo da abordagem das capacidades não se limita ao que uma pessoa realmente faz, mas abrange, também, o que ela é capaz de fazer, escoIhendo ou não aproveitar essa oportunidade.

Uma exemplificação dessa perspectiva pode ser extraída da situação de privação de alimentos. No entendimento de Sen (2011) uma pessoa que, tendo oportunidade de acessar alimentos, opta por jejuar por qualquer motivo - religioso, político, pessoal, etc. - está em uma situação bastante diversa daquela que se vê privada de alimentos por não ter opção de acessá-los, por circunstâncias econômicas pessoais ou pela falta coletiva de alimentos ocasionada por alguma circunstância econômica ou ambiental. Ambos os cenários têm o mesmo resultado, qual seja, privação de acesso a alimentos, mas há uma distância considerável na liberdade manifesta em cada um deles.

Essa proposição de Sen aproxima-se do conceito de liberdade proposto por Hannah Arendt em uma palestra datada de 1966-1967, na qual a autora destaca que "[...] [a]penas aqueles que conhecem a liberdade em relação à necessidade podem apreciar por completo o significado da liberdade em relação ao medo, e só aqueles que estão livres de ambos - necessidade e medo - têm condições de conceber uma paixão pela liberdade pública" (ARENDT, 2018, p. 34).

Nos seus apontamentos, Amartya Sen realça também dois papéis das liberdades: constitutivo e instrumental. $O$ primeiro refere-se à importância da liberdade substantiva no enriquecimento da vida humana. Essas liberdades substantivas são as capacidades elementares, tais como ter condições de evitar privações, de ter participação política, liberdade de expressão. Na perspectiva constitutiva, o desenvolvimento envolve a expansão dessas e de outras liberdades humanas, e sua avaliação deve se basear nessa consideração. Assim, na concepção do desenvolvimento como liberdade, a participação e a dissenção políticas são partes constitutivas do próprio desenvolvimento, independentemente de condições econômicas (SEN, 2010).

O papel instrumental refere-se ao modo como diferentes tipos de direitos, oportunidades e intitulamentos contribuem para a expansão da liberdade humana e consequentemente para a promoção do desenvolvimento. Nessa senda, Sen (2010) aponta que a eficácia 
da liberdade como instrumento concentra-se no fato de que diferentes tipos de liberdade são inter-relacionados, de modo que um tipo de liberdade pode contribuir imensamente para promover liberdades de outros tipos, encontrando-se as liberdades associadas. Contribuem, portanto, para a liberdade global que as pessoas têm para viver como desejariam.

Em um rol exemplificativo, Sen (2010) aborda especificamente cinco liberdades instrumentais, embora a lista não seja exaustiva: liberdades políticas, facilidades econômicas, oportunidades sociais, garantias de transparência e segurança protetora.

A segurança protetora consiste na disponibilidade de uma rede de segurança social, que inclui benefícios aos desempregados, suplementos de renda, distribuição de alimentos ou empregos públicos de emergência para gerar renda aos necessitados, impedindo, assim, que a população seja submetida à miséria, à fome ou mesmo à morte (SEN, 2010).

As garantias de transparência relacionam-se à liberdade das pessoas de lidarem umas com as outras sob garantias de clareza e de ausência de segredo e têm um papel de inibir a corrupção, a irresponsabilidade financeira e transações ilícitas (SEN, 2010).

As oportunidades sociais tratam de medidas adotadas nas áreas de educação, saúde, etc., que têm influência na liberdade substantiva do indivíduo de viver melhor. São importantes não apenas para a condução da vida particular, mas também para uma participação efetiva em atividades econômicas e políticas (SEN, 2010).

As facilidades econômicas referem-se às oportunidades de utilizar recursos econômicos para consumo, produção ou troca, com atenção especial ao modo como as rendas são distribuídas (SEN, 2010).

As liberdades políticas, enfim, desempenham um papel importante na teoria de Amartya Sen. São aquelas que todos possuem de escolher quem deve governar e que princípios devem reger a comunidade, constituindo, também, as possiblidades de fiscalização e controle da gestão pública. Por meio dessas liberdades os cidadãos podem criticar, discutir e expressar sua vontade diante das autoridades, bem como exigir a promoção de serviços públicos de qualidade e buscar a responsabilidade dos gestores (SEN, 2010).

Nesse passo, Sen (2010) aponta que nunca houve em uma sociedade realmente democrática situações de fome coletiva, pois a necessidade dos governantes de se submeterem a eleições com voto livre dos cidadãos e a alternância no poder fazem com que as necessidades dos indivíduos sejam consideradas com mais cautela.

Ainda, o enfoque das capacidades destaca que diferentes tipos de liberdades se relacionam entre si, contribuindo mutuamente para se complementarem e se promoverem, como uma via de mão dupla, de modo que o aumento das capacidades individuais mediante a participação na escolha social e nas tomadas de decisão públicas, por exemplo, amplia o progresso de outras capacidades, que reflexamente aumentam a liberdade. Destarte, as políticas públicas escolhidas para uma sociedade podem aumentar as capacidades dos indivíduos do mesmo modo que a direção da política pública pode sofrer influência pelo uso efetivo das capacidades pelos indivíduos da sociedade (SEN, 2010).

A perspectiva das capacidades humanas relaciona-se, então, à liberdade substantiva de levar a vida que se tem razão para desejar e aperfeiçoar as escolhas e as oportunidades que cada um possui e são importantes na medida em que têm relevância direta para o bem-estar, 
para a dignidade humana e influenciam diretamente na promoção de mudanças sociais e no aumento da produção econômica.

É interesse frisar em prol da perspectiva das capacidades de Amartya Sen que a renda é apenas útil para a liberdade. Ausente a renda, há certamente a privação para desempenhar certas atividades e também para ter acesso a diversas capacidades e liberdades humanas. A renda, contudo, por si só não é liberdade. Ela permite ou facilita o acesso à liberdade, caracterizando-se como um (e não único) instrumento que facilita o acesso às liberdades (SEN, 2011). Assim, garantir as próprias liberdades em vez de um instrumento capaz de facilitar o acesso às liberdades parece ser um caminho mais bem desenhado para atingir o efetivo acesso às liberdades.

Mesmo porque diversos fatores podem influenciar na relação entre o nível de renda e de oportunidades, como heterogeneidades pessoais - diferenças na relação entre renda e as necessidades de cada pessoa para aplicar a renda no desenvolvimento de capacidades - diversidades no ambiente físico - como condições ambientais de cada localidade (terremotos, inundações, secas, invernos rigorosos, etc.) implicam a vida das pessoas e a determinação das suas necessidades - variações sociais - acesso à saúde, educação pública, segurança, transporte público, etc. - diferenças de perspectivas relacionais - como características culturais e personalidade dos indivíduos (SEN, 2010).

Sen pensa a distribuição de bens em uma sociedade de maneira inovadora. Sua abordagem possui semelhanças com a igualdade de bens primários de Rawls, em detrimento da igualdade de bem-estar. $\mathrm{O}$ autor indiano, todavia, propõe algo a mais, pois para ele não basta igualar as pessoas em renda e riquezas, é preciso que elas sejam iguais na capacidade de transformar a renda e riqueza em capacidade real de realizações, consideradas as diversidades entre as pessoas.

Destarte, investimentos em políticas públicas como educação, saúde, moradia, mobilidade urbana, saneamento básico, que são destinados à concretização das liberdades, não podem ser vistos como meros meios para alcançar o aumento de renda da população atingida. Deve-se buscar mais do que isso. Essas políticas públicas possibilitam o exercício da cidadania e o alargamento de oportunidades para levar a vida que se deseja, bem como a ampliação das próprias liberdades em suas diversas formas.

Nesse passo, a discussão pública e participação social são, para Sen, centrais para a elaboração de políticas em uma estrutura democrática, pois “[...] [e]m uma abordagem orientada para a liberdade, as liberdades participativas não podem deixar de ser centrais para a análise de políticas públicas" (SEN, 2010, p. 149).

Para a perspectiva das capacidades não é, portanto, o desenvolvimento econômico que garante o êxito de uma sociedade, pois esse não assegura o desenvolvimento social. De outra banda, investir em políticas públicas eficientes e garantir as liberdades dos indivíduos pode gerar um desenvolvimento econômico para o país em longo prazo, conferindo-se ao desenvolvimento um aspecto mais qualitativo do que quantitativo.

Esse olhar tem especial relevância em um país como o Brasil, no qual a desigualdade social foi herdada do passado, é produzida e reproduzida no presente. Nesse sentido, Schwarcz (2019) destaca que a desigualdade social tende sempre a aumentar em países que oferecem 
poucas oportunidades de emprego, apresentam investimento discreto nas áreas sociais e não estimulam o consumo de bens culturais.

Como há uma grande quantidade e variedade de componentes do bem-estar real das pessoas, a abordagem das capacidades tem dificuldades em atribuir pesos às diferentes características pessoais, tendo em vista sua vasta multiplicidade e multidimensionalidade. Não há uma fórmula correta para atribuir pesos aos diversos funcionamentos individuais e o próprio Sen rejeita as tentativas de construir índices sintéticos ou algoritmos para escalonar as capacidades e liberdades humanas. Em vez disso, Sen (2011, p. 412) propõe um "[...] sistema de pesos não lexicais", que leva em conta cada contexto e consequências específicas sem um escalonamento predeterminado das capacidades e liberdades pessoais.

Com esse método, elegem-se certos funcionamentos tidos como relevantes em determinado espaço e tempo. Do ponto de vista de avaliação social abrangente, a atribuição de pesos a funcionamentos sociais demandará uma espécie de consenso, resultado de uma escolha social, que poderá se constituir em objetivos de políticas públicas. Aqui revela-se imprescindível uma construção coletiva, com a participação da sociedade em discussões abertas, livres, públicas e racionais. Reforçando o que foi mencionado alhures, essa construção coletiva não se resume à garantia da adequada representação parlamentar, mas abrange a existência de uma estrutura que garanta a participação no processo decisório e que contribua positivamente para a ampliação das capacidades.

Sendo assim, o desenvolvimento como liberdade proposto por Amartya Sen aborda elementos e proporciona ferramentas importantes para pensar na formulação, desenvolvimento e execução de políticas públicas de maneira mais inclusiva e preocupada com as reais necessidades das pessoas que vivem em uma sociedade democrática.

Sen aborda a liberdade com um significado negativo de ausência de interferência do Estado na esfera privada, mas afirma que a liberdade está relacionada à expansão das capacidades, ou seja, à ampliação das possibilidades de escolha que as pessoas podem ter para levarem a vida que valorizam (SEN, 2010).

A concepção de justiça de Sen relaciona-se às particularidades de cada pessoa e às privações pelas quais passam. Considerar o modelo de justiça social centrado nas realizações implica a ampliação das liberdades substanciais. Assim, a ideia de liberdade não pode ser dissociada da realização da igualdade no seu sentido material, o que traduz os direitos sociais como prioritários para proporcionar a igualdade de capacidades, pois a privação desses direitos afeta diretamente a capacidade de escolha e autonomia das pessoas.

Delineados os conceitos gerais da teoria de Amartya Sen, o próximo tópico cuida de destacar as críticas de Sen à teoria rawlsiana.

\section{AS CRÍTICAS DE AMARTYA SEN À JUSTIÇA COMO EQUIDADE}

No decorrer da sua obra, Sen destaca admiração por Rawls, inclusive dedicando à sua memória o livro "A teoria da justiça". Essa admiração e respeito evidentes, contudo, não impedem Sen de tecer críticas que entende pertinentes à teoria rawlsiana. Ao acessar as obras de Sen, nota-se um diálogo próximo à justiça como equidade de Rawls, razão pela qual este tópico não 
tem por finalidade esgotar o assunto, mas apenas apontar a relação feita pelo próprio Sen entre sua teoria e a de John Rawls e os avanços propostos por Sen à justiça como equidade.

No diálogo com a teoria rawlsiana, Sen propõe um enfoque diferente para tratar das desigualdades sociais, que resultam em conversão de renda e riqueza variadas segundo a forma de vida que cada pessoa pode levar.

A primeira consideração de Sen nesse sentido refere-se à escolha de princípios aplicáveis a toda estrutura social na posição original. Sen destaca que Rawls naturalmente em sua linha de raciocínio parte de um pressuposto institucionalista de justiça distributiva, no qual busca acertar as instituições, sem se concentrar em sociedades reais (SEN, 2011).

Na perspectiva de Sen (2011), no entanto, há interesses plurais e eventualmente conflitantes, que afetam a compreensão de justiça e não precisam divergir de modo que somente um conjunto de princípios compreenda a imparcialidade e a equidade, enquanto outros não. Nesse sentido, diante da pluralidade de concepções de justiça não abrangidas por um único conjunto de princípios escolhidos, não é possível que uma teoria da justiça mantenha-se focada em instituições justas geridas por determinados princípios. Para Sen, a imparcialidade pode ter muitas formas e manifestações.

Por isso, diante da pluralidade de princípios que se relacionam às concepções de justiça, na dimensão seniana, não é possível que um único conjunto de princípios seja escolhido. Para exemplificar o raciocínio, Sen trata de três crianças que reivindicam uma flauta. Uma, Anne, é a única que sabe tocar o instrumento; Bob é o mais pobre entre os três e Carla alega ter produzido o objeto, por isso deve ser seu. Diferentes concepções de justiça, como utilitarismo, igualitarismo econômico, libertarismo, poderiam ofertar soluções, sustentando cada uma como a mais correta para a problemática de quem deveria ficar com a flauta (SEN, 2011).

No exemplo citado, identificam-se três argumentos diferentes quanto às pretensões da justiça: a busca da satisfação, a eliminação da pobreza e o direito de obter os frutos do próprio trabalho. Cada um desses argumentos indica uma solução diferente, a partir de razões imparciais e não arbitrárias, por isso um conjunto único de princípios não é, para Sen, suficiente para solucionar problemas de justiça.

A segunda crítica de Sen refere-se à prioridade da liberdade proposta por Rawls. Os princípios de justiça da teoria rawlsiana atribuem prioridade lexical à liberdade de cada pessoa, sujeita à liberdade semelhante para todas, em relação a outras considerações. Assim, as liberdades que todos podem desfrutar não podem ser violadas em virtude da promoção da riqueza ou renda, ou para distribuir recursos econômicos entre as pessoas (RAWLS, 2008).

Sen considera extrema essa previsão de Rawls. Embora reconheça que as liberdades formais têm um papel importante, Sen considera que o reconhecimento delas não pode resultar na desconsideração de outras necessidades. Diante disso, questiona: "por que deveríamos considerar a forme coletiva, a fome individual e a negligência médica invariavelmente menos importantes o que a violação de qualquer tipo de liberdade pessoal?" (SEN, 2011, p. 95-96).

A terceira e talvez mais extensa crítica de Sen à justiça como equidade formulada por Rawls, que define a estrutura da perspectiva seniana, relaciona-se à métrica dos bens primários. Rawls (2008) utiliza bens primários (direitos, liberdades, oportunidades, riqueza, renda e as bases social do autorrespeito) como base para sua proposta de justiça distributiva. Sen 
(2010, 2011), no entanto, aponta que a métrica baseada em bens primários não considera as variações pessoais para converter bens primários em bem-viver. Diante disso, propõe a mudança de foco dos bens primários para uma avaliação real das liberdades e capacidades.

Assim, para Sen (2011), os bens primários são recursos para satisfação das necessidades dos indivíduos, contudo o uso dos recursos para realizar coisas valiosas ao indivíduo depende de um conjunto de variáveis, tais como características pessoais, local onde as pessoas vivem, circunstâncias climáticas, renda, etc. Nessa linha de raciocínio, se o contexto é diferente, a capacidade que cada pessoa tem de transformar o seu quinhão de bens no que é valioso para si também é variada.

A proposta de Sen não se fixa, portanto, na igualdade de bens primários, pois a igualdade somente ocorrerá quando forem avaliadas as capacidades que cada indivíduo tem de converter os recursos em liberdades.

Sen não descarta o modo como Rawls compreende as liberdades, mas propõe uma visão mais ampla, uma liberdade mais abrangente para realizar o modo de vida que cada um tem razão para valorizar. Acrescenta, assim, à ideia de liberdade a necessidade de proporcionar condições de liberdades materiais às pessoas, considerando as diversidades pessoais, ambientais e de recursos para transformar as oportunidades em capacidades.

A crítica de Sen localiza-se, portanto, na insuficiência da teoria de justiça de Rawls ao concentrar-se em um ideal de justiça baseado em instituições justas, sem analisar a aplicação prática desse ideal às sociedades e instituições reais. É a partir desse enfoque crítico que Sen elabora sua concepção de justiça social, baseada nas teorias da escolha social.

Rawls interpretou a proposta de Sen como baseada em uma doutrina particular abrangente, que tende a hierarquizar as distintas conquistas e estilos de vida das pessoas. Sen assegura, entretanto, que o enfoque que defende objetiva refletir a liberdade de cada indivíduo para escolher formas de vida alternativas e não depende da unanimidade de objetivos específicos (GARGARELLA, 2008).

De fato, a proposta de Rawls da métrica de bens primários corre o risco de ser demasiadamente objetiva. Nesse ponto ganha relevância a busca formulada por Sen, destinada a encontrar um ponto intermediário entre posições objetivistas e subjetivistas. A proposta de Sen não invalida a teoria de Rawls, mas lhe confere uma perspectiva mais voltada à utilização das instituições como instrumento de justiça, e não como seu fundamento. $O$ estudo aprofundado dessa perspectiva é, sem dúvida, um caminho que trará benefícios à proposta igualitarista e às sociedades democráticas modernas.

Por outro lado, não se pode deixar de observar que os direitos básicos dos indivíduos são assegurados no âmbito de cada Estado e por meio de suas instituições. Assim, uma teoria da justiça que se afaste de um modelo ideal de justiça ou de sociedade justa a partir das instituições corre o risco de não avançar na eliminação das injustiças e tornar-se irrealizável.

Diante disso, a postura de Sen de não rejeitar em absoluto a teoria rawlsiana, mas de buscar somar a ela elementos importantes e não considerados pelo autor, tornando-a mais realizável na sociedade, pode ser um modelo interessante de complementariedade a ser perseguido. 
O desenvolvimento como liberdade proposto por Amartya Sen aborda elementos e proporciona ferramentas importantes para pensar na teoria da justiça de maneira mais inclusiva e preocupada com as reais necessidades das pessoas que vivem em uma sociedade democrática, reunido em um único questionamento o que seriam as instituições justas e como elas seriam capazes de promover justiça real.

\section{CONCLUSÃO}

Abordados os aspectos gerais e que interessam ao debate nas teorias de John Rawls e de Amartya Sen, é possível concluir que, a despeito de existirem divergências entre os pontos de vista dos autores, as teorias têm muitos aspectos de convergência, na medida em que ambas se dedicam a formular concepções de justiça de abordagem igualitarista e buscam soluções para as desigualdades em sociedades democráticas contemporâneas. Desse modo, analisadas conjuntamente, mostram-se relevantes em sociedades plurais e desiguais como a que vivemos.

A abordagem de Sen pode lidar melhor com as diferenças individuais, como doenças, deficiências físicas, relativas a variações individuais de funcionamentos, bem como com diferenças em contexto econômico, pois é focada nos fins e não nos meios. É, em tese, uma abordagem mais sensível às diferenças. Havendo diferenças entre as pessoas nesses aspectos variados, há situações que precisam de mais recursos para satisfação de necessidades que outras. Nessa abordagem, o foco em bens primários apresenta-se de fato mais limitada.

Rawls, por sua vez, almeja igualar as pessoas em liberdades, direitos, igualdade, bens materiais e autorrespeito, que são os chamados bens primários imprescindíveis para realizar qualquer plano de vida, considerando a diversidade humana. Essa abordagem é, sem dúvidas, importante para a liberdade real das pessoas.

Sen, no entanto, acredita que esse enfoque não é suficiente. Por isso, deseja igualar as pessoas na liberdade de funcionamentos. Para Sen as pessoas só são iguais nos direitos e liberdades se forem proporcionadas condições iguais, considerando as peculiaridades de cada situação, moldadas pela capacidade que têm de converter sua liberdade em vida boa.

A postura de Sen de não rejeitar em absoluto a teoria rawlsiana, mas de buscar somar a ela elementos importantes e não considerados pelo autor, tornando-a mais realizável na sociedade, pode ser um modelo interessante de complementariedade a ser perseguido.

O desenvolvimento como liberdade proposto por Amartya Sen aborda elementos e proporciona ferramentas importantes para pensar na teoria da justiça de maneira mais inclusiva e preocupada com as reais necessidades das pessoas que vivem em uma sociedade democrática, reunindo em um único questionamento o que seriam as instituições justas e como elas seriam capazes de promover justiça real.

\section{REFERÊNCIAS}

ARENDT, Hannah. Liberdade para ser livre. Tradução Pedro Duarte. Rio de Janeiro: Bazar do Tempo, 2018.

FREEMAN, Samuel Richard. Rawls. Oxon; New York: Routledge, 2007.

GARGARELLA, Roberto. As teorias de justiça depois de Rawls: um breve manual de filosofia política. Tradução Alonso Reis Freire. São Paulo: WMF Martins Fontes, 2008. 
JOHNSTON, David. Breve história da justiça. Tradução Fernando Santos. São Paulo: Editora WMF Martins Fontes, 2018.

RAWLS, John. Uma teoria da justiça. Tradução Jussara Simões. 3. ed. São Paulo: Martins Fontes, 2008.

RAWLS, John. O liberalismo político. Tradução Álvaro de Vita. ed. ampl. São Paulo: Editora WMF Martins Fontes, 2011.

SCHWARCZ, Lilian Moritz. Sobre o autoritarismo brasileiro. 1. ed. São Paulo: Companhia das Letras, 2019.

SEN, Amartya. Desenvolvimento como liberdade. Tradução Laura Teixeira Motta. São Paulo: Companhia das Letras, 2010.

SEN, Amartya. A ideia de justiça. Tradução Denise Bottmann e Ricardo Doninelli Mendes. 1. ed. São Paulo: Companhia das Letras, 2011. 